\title{
Risk Analysis and Determination of Aluminum Concentration in Jellyfish (Rhopilema Esculentum)
}

\author{
Yong-Fu SHI ${ }^{1}$, Qian-Yun ZHAN ${ }^{1,2}$, Liang-Liang TIAN ${ }^{1}$, Run-Run \\ GU $^{1}$, Dong-Mei HUANG ${ }^{1}$, Feng HAN ${ }^{1}$, Yuan WANG ${ }^{1}$, Xuan-Yun \\ HUANG $^{1}$, You-Qiong CAI ${ }^{1, *}$ \\ ${ }^{1}$ Fishery Products Quality Inspection and Test Center (Shanghai) of the Ministry of \\ Agriculture, Shanghai, China \\ ${ }^{2}$ Food Science and Engineering College, Ocean University of China, Qingdao, China \\ ${ }^{*}$ Corresponding author
}

Keywords: Fishery products safety, Aluminum, Salted jellyfish, Risk analysis.

\begin{abstract}
The concentration of aluminum in salted jellyfish (Rhopilema esculentum) was determined and samples were collected from market located in Shanghai. Risk of aluminum in salted jellyfish was analyzed in the present study. 16 samples were collected from markets in Shanghai, including instant jellyfish and raw salted jellyfish. The results show that the aluminum concentrations of samples ranged from $126.9 \mathrm{mg} / \mathrm{kg}$ to $489.2 \mathrm{mg} / \mathrm{kg}$. In the present study, the concentration of aluminum from different tissues of jellyfish was detected, and the results indicated that there was no significant difference between different tissues. And the risk was analyzed by intake of jellyfish according to the WHO regulations. The analysis results showed that when aluminum concentration exceeded $1000 \mathrm{mg} / \mathrm{kg}$, The PTWI value would exceeded the limit of $2 \mathrm{mg} / \mathrm{kgbw}$ stipulated in WHO regulations. The aluminum intake from salted jellyfish would not influence consumers' health under normal living mode.
\end{abstract}

\section{Introduction}

Jellyfish (Rhopilema esculentum)is a kind of marine coelenterate animals, and in China, it is widely distributed in North and south sea. It is a kind of famous and popular fishery products in China as a traditional economic species [1,2]. The jellyfish umbrella and head were separated for further processing. Fresh jellyfish is mainly composed of collagen and water, and it is nutritious. Jellyfish contains $12.3 \mathrm{~g}$ protein, $4.3 \mathrm{~g}$ carbohydrate, $182 \mathrm{mg}$ calcium, $132 \mu \mathrm{g}$ iodine and a variety of vitamins. It is described as a kind of products with high medicinal value in Compendium of Materia Medica [3]. Since ancient times in China, people began to find ways for jellyfish processing [1].

The main component of fresh jellyfish is water, Potassium alum $\left(\mathrm{KAl}\left(\mathrm{SO}_{4}\right)_{2} .12 \mathrm{H}_{2} \mathrm{O}\right)$ is used as dehydrating agent and coagulant. Fresh jellyfish is first dehydrated by potassium alum, and it is salted by mixture of salt and potassium alum with a certain proportion [4]. As the special processing method of jellyfish, so the product contains high concentration of potassium alum, resulting in higher aluminum content in jellyfish products. Excessive aluminum intake will affect the absorption of calcium and iron, resulting human osteoporosis anemia and even affect the development of nerve cells potentially, severe cases lead to Alzheimer's disease [4].

In 1988 the World Health Organization officially established aluminum as food pollutant, and its use and residual condition were strictly controlled, and the PTWI value of aluminum was $2 \mathrm{mg} / \mathrm{kgbw}$ [5]. The content of potassium alum in the jellyfish 
products is not higher than $2.2 \%$ stipulated in the aquaculture industry standard [6]. In the present study, instant and raw salted jellyfish were detected through random sampling from local markets in Shanghai. The concentration of aluminum was determined by Inductively coupled plasma mass spectrometry (ICP/MS), comparison of aluminum content between instant and raw salted jellyfish was carried out, and evaluate the risk and safety of jellyfish on sale. And this is meaningful for consumers to eat jellyfish, and it also provides the administrators with valuable data.

\section{Experiment}

\section{Instrument}

Inductively Coupled Plasma Mass Spectrometry (ICP-MS) was purchased from Agilent. Electric heating panel was obtained from LabTech. Homogenizer was purchased from Philips. Deionised water which was from a MilliQ water purification system was used for the preparation of all solutions.

\section{Reagent}

Nitric acid and magnesium nitrate hexahydrate were all obtained from Sinopharm Chemical Reagent Co., Ltd. Hydrogen peroxide was purchased from Aladdin.

\section{Sample Pretreatment}

8 instant samples and 8 raw salted samples were all collected from Metro Supermarket, TongChuan market and Lotus supermarket randomly in Shanghai. The total 16 jellyfish samples were stored at $4^{\circ} \mathrm{C}$ after purchased.

\section{Pretreatment Method}

Instant Samples Processing Procedure. After opening the package, put the samples into the sifter to control water for $5 \mathrm{~min}$. Then $100 \mathrm{~g}$ sample was homogenized individually.

Raw Salted Samples Processing Procedure. Non-soak samples: cut the jellyfish head or skin into small pieces. Then put these $100 \mathrm{~g}$ pieces into the Spider to control water for $5 \mathrm{~min}$ and homogenize later.

Soak samples: cut the jellyfish head or skin into small pieces and put $100 \mathrm{~g}$ samples into the Spider to control water for $5 \mathrm{~min}$. Then the samples were soaked in $200 \mathrm{~g}$ water for $4 \mathrm{~h}$. Changed the water per hour. Subsequently, got out the samples to control water and homogenize.

\section{Samples Digestion}

In order to ensure the uniformity of samples, $10 \mathrm{~g}$ samples were weighed in digestion vessels. Then $15 \mathrm{~mL}$ nitric acid and $5 \mathrm{~mL}$ hydrogen peroxide were added. After the reaction grew to be flat, the digestion vessels were placed on the electric heating panel for wet-digestion. Setting to $160^{\circ} \mathrm{C}$, the samples were fully digested. Then cooling to room temperature, the digested samples were diluted in water up to $100 \mathrm{~mL}$. The $0.1 \mathrm{~mL}$ samples obtained was made up to the final volume of $100 \mathrm{~mL}$ with deionized water. 


\section{Determination Method}

\section{ICP/MS}

ICP/MS is used for determining aluminum concentration with scandium $(\mathrm{Sc})$ as internal standard.

\section{Calibration}

The concentration of stock is $10 \mu \mathrm{g} / \mathrm{mL} .1 \% \mathrm{HNO}_{3}$ water-solution was used for diluting the stock. And the linear range of determination is from $0.1 \mathrm{ppm}$ to $1.0 \mathrm{ppm}$, the concentration of Sc is $0.5 \mathrm{ppm}$.

\section{Results of Detection}

The concentration of $\mathrm{Al}$ in 8 instant samples ranges from $164.4 \mathrm{mg} / \mathrm{kg}$ to $489.2 \mathrm{mg} / \mathrm{kg}$. $37.5 \%$ samples are $100 \sim 200 \mathrm{mg} / \mathrm{kg}$. $12.5 \%$ samples are $200 \sim 300 \mathrm{mg} / \mathrm{kg}$. There are 3 samples in the $400 \sim 500 \mathrm{mg} / \mathrm{kg}$. And only one sample is in the range of $300 \sim 400 \mathrm{mg} / \mathrm{kg}$.

The concentration of 8 raw salted samples differ from $126.9 \mathrm{mg} / \mathrm{kg}$ to $475.3 \mathrm{mg} / \mathrm{kg}$. Five samples are in the $100 \sim 200 \mathrm{mg} / \mathrm{kg}$. Two samples are in the $300 \sim 400 \mathrm{mg} / \mathrm{kg}$. Besides, one sample is in the $400 \sim 500 \mathrm{mg} / \mathrm{kg}$.

The result was showed in Table 1 in details.

Table 1. the concentration of each sample

\begin{tabular}{|c|c|c|c|}
\hline $\begin{array}{c}\text { Sample } \\
\text { name }\end{array}$ & $\begin{array}{l}\text { content } \\
(\mathrm{mg} / \mathrm{kg})\end{array}$ & $\begin{array}{c}\text { Sample } \\
\text { name }\end{array}$ & $\begin{array}{r}\text { content } \\
(\mathrm{mg} / \mathrm{kg})\end{array}$ \\
\hline Instant jellyfish head & 180.2 & Jellyfis head & 475.3 \\
\hline Instant jellyfish umbrealla & 489.2 & jellyfish umbrealla & 126.9 \\
\hline Instant jellyfish umbrealla & 164.4 & jellyfish head & 154.8 \\
\hline Instant jellyfish umbrealla & 403.6 & jellyfish umbrealla & 183.4 \\
\hline Instant jellyfish umbrealla & 261.5 & jellyfish head & 199.4 \\
\hline Instant jellyfish umbrealla & 368.4 & jellyfish head & 174.4 \\
\hline Instant jellyfish umbrealla & 473.4 & jellyfish umbrealla & 367.9 \\
\hline Instant jellyfish umbrealla & 168.2 & jellyfish umbrealla & 375.5 \\
\hline
\end{tabular}

\section{Risk Analysis of Aluminum in Jellyfish Products}

\section{PTWI of Aluminum from WHO Regulations}

According to FAO / WHO seventy-fourth conference on food additives and contaminants, the assessment report data shows that the maximum allowable intake of aluminum compound (PTWI) was determined to be $2 \mathrm{mg} / \mathrm{kgbw}$ [7].

\section{The Aluminum Content of Food in Hong Kong}

From August 2007 to October 2008, Hong Kong government carried on an investigation of aluminum content, including steamed or bakery food, salted products and other seven categories of food containing aluminum. And in 2009, a report of risk assessment of food containing aluminum was issued [5].The report shows that aluminum was detected in $97 \%$ of the samples, and the average content of aluminum is between $1-2600 \mathrm{mg} / \mathrm{kg}$, the food with the highest content of aluminum is the baked / fried food ingredients powder, ranging from $180-16000 \mathrm{mg} / \mathrm{kg}$ [8]. 15 instant jellyfish samples were detected, the aluminum content ranging from $400-1800 \mathrm{mg} / \mathrm{kg}$ [8]. 


\section{The Consumption of Jellyfish Products in China}

In China, There are several provinces producing jellyfish including Shandong, Jiangsu, Zhejiang, Shanghai, Liaoning, Fujian and Guangdong [5]. Its consumption are mainly concentrated in the eastern coastal provinces. According to the report, in 2012 in Qingdao, the annual sales of jellyfish products exceeded 50,000kg [9]. Compared to other fishery products, the amount of jellyfish is small.

In the risk assessment of Hong Kong released in 2009, the hazard assessment of adult intake from aluminum components were assessed, the value was estimated at $0.6 \mathrm{mg} / \mathrm{kgbw} / \mathrm{w}$, the aluminum intake contributed from jellyfish was $0.06 \mathrm{mg} / \mathrm{kgbw} / \mathrm{w}$, accounted for $10 \%$ of the total food intake of aluminum [8].

\section{Risk Analysis of Jellyfish Intake}

Alum is a necessary additive in jellyfish processing [10]. In the valid aquaculture industry standard (SC/T 3210-2001) [11], alum content should be in the range of $1.2-2.2 \%(12000-22000 \mathrm{mg} / \mathrm{kg})$, that means the content of aluminum ranged from 684 to $1250 \mathrm{mg} / \mathrm{kg}$; the market sampling and reported research results show that the aluminum content of the majority of samples exceeded $100 \mathrm{mg} / \mathrm{kg}$, and the Hong Kong risk assessment report showed that the weekly intake of aluminum from adult contributed by jellyfish is only $0.06 \mathrm{mg} / \mathrm{kgbw}$, accounting for $10 \%$ of the total intake [8]; and Zhang [5] reported that grain is the main source of dietary intake of aluminum for Chinese residents, aluminum from fishery intake only accounted for $0.2 \%$ compared with the total intake, while the jellyfish intake proportion is much more smaller. At present, the PTWI from WHO is $2 \mathrm{mg} / \mathrm{kgbw}$ [12], it is supposed that the average adult body weight is $60 \mathrm{~kg}$, the highest intake of aluminum for each adult weekly is $120 \mathrm{mg}$, according to the Hong Kong report[8], jellyfish accounted for $10 \%$ of the total intake of aluminum, each adult tolerable weekly intake of aluminum amount is $12 \mathrm{mg}$ from jellyfish, assuming that the average weekly consumption of jellyfish is $10 \mathrm{~g}$ (according to Hong Kong's assessment report), when the aluminum content in jellyfish reached $1200 \mathrm{mg} / \mathrm{kg}$ can meet the requirements of WHO's PTWI value[7,13]. In accordance with Zhang's research [5], Chinese residents main sources of dietary intake of aluminum is grain, the total contribution of fishery aluminum intake is $0.2 \%$, the amount of aluminum intake from jellyfish is in a safe range.

\section{Acknowledgement}

This study was supported by the special research fun for national non-profit of East China Sea Fishery research institute(NO.2011M12) and Agriculture industry research special funds for public welfare projects(201503108-EC-1).

\section{References}

[1] C. Yang, X.R. Su, T.W. Li, Comprehensive utilization of jellyfish, J. Hebei Fish.2 (2003) 12-14.

[2] Y.F. Yang, F.F. Huang, G.F. Ting, Research progress on chemical compositions and bioactivities of Jellyfish,J. Zhejiang Ocean University. 28 (2009) 86-90.

[3] H. Morishige, T. Sugahara, S. Nishimoto, A. Muranaka, F. Ohno, R. Shiraishi, M. Doi, Immunostimulatory effects of collagen from jellyfish in vivo, J. Cytotechnol. 63 (2011) 481-492. 
[4] J. Pang, Progress in study on aluminum toxicity to the human body and the related food safety, J. International Method.6 (2011) 470-473.

[5] X. Zheng, Influence of aluminum to people's health and testing the content of aluminum food, J. Chongqing University Science Technology. 9 (2007) 36-37.

[6] X.Q. Yang, L.H. Li, Y.Y. Wu, S.Q. Diao, L.D. Li, P.J. Chen, S.X. Hao, Studies on the processing technology and formula of ready-to-eat jellyfish ,J. South China Fish Science. 1 (2005) 46-50.

[7] F.J. Ding, Y.Y. Li, J.J. Xu, X.R. Su, X. Gao, F.P. Yue, Study on effect of jellyfish collagen hydrolysate on anti-fatigue and anti-oxidation, J. Food Hydrocolloids. 25 (2011) 1350-1353.

[8] Hong Kong. Report on risk assessment of Aluminum in food. 2009.

[9] C.S. Liang, S.G. Hu, J. Wang, H. Li , Improving the method for detecting aluminum in food and its application in risk monitoring ,J. Chinese Journal of Food Hygiene. 24 (2012) 97-101.

[10] G.Q. Cang, Determination of aluminum in jellyfish by Chroma-zurol $S$ spectrophotometric method, J. Capital Journal of Public Health. 4 (2010) 281-282.

[11] SC/T 3210-2001. Salted jellyfish and salted jellyfish head.

[12] WHO. Evaluation of certain food additives and contaminants: sixty-seventh report of the Joint FAO/WHO Expert Committee on Food Additives. WHO Technical Report Series 940. Geneva: WHO; 2007.

[13] V. Fekete, S. Vandevijvere, F. Bolle, J. van Loco, Estimation of dietary aluminum exposure of the Belgian adult population: Evaluation of contribution of food and kitchenware, J. Food Chemical Toxicology. 55 (2013) 602-608. 